\title{
Effect of dexamethasone gargle, intravenous dexamethasone, and their combination on postoperative sore throat: a randomized controlled trial
}

\section{Seunghee Ki', Inwook Myoung', Soonho Cheong', Sehun Lim', Kwangrae Cho ${ }^{1}$, Myoung-hun Kim ${ }^{1}$, Yongjae Han ${ }^{1}$, Minkyung $\mathrm{Oh}^{2}$, Yohan Park ${ }^{3}$, Kwanghee $\mathrm{Kim}^{3}$, and Jeonghan Lee ${ }^{1}$}

Received June 25, 2020

Revised September 25, 2020

Accepted October 5, 2020 Medicine, Busan, Korea

\section{Corresponding author}

Jeonghan Lee, M.D., Ph.D

Department of Anesthesiology and

Pain Medicine, Inje University Busan

Paik Hospital, Inje University College

of Medicine, 75 Bokji-ro, Busanjin-gu,

Busan 47392, Korea

Tel: 82-51-890-6520

Fax: 82-51-898-4216

E-mail: ljh646@inje.ac.kr
'Department of Anesthesiology and Pain Medicine, ${ }^{2}$ Department of Pharmacology, ${ }^{3}$ Department of Surgery, Inje University Busan Paik Hospital, Inje University College of

Background: Postoperative sore throat (POST) is a complication that decreases patient satisfaction and increases postoperative complaints. The present study was conducted to investigate effects of gargling with dexamethasone, intravenous dexamethasone injection and the combination of the two on the incidence and severity of POST.

Methods: Study participants were 96 patients who had undergone laparoscopic cholecystectomy, randomly allocated into three groups. Group G gargled with $0.05 \%$ dexamethasone solution and were infused intravenous 0.9\% normal saline before general anesthesia; group I gargled with $0.9 \%$ normal saline and were infused intravenous $0.1 \mathrm{mg} / \mathrm{kg}$ dexamethasone; group Gl gargled with $0.05 \%$ dexamethasone solution and were infused intravenous 0.1 $\mathrm{mg} / \mathrm{kg}$ dexamethasone. The incidence and severity of POST, hoarseness and cough were evaluated and recorded at 1, 6, and $24 \mathrm{~h}$ after the surgery.

Results: There were no significant differences in the total incidence of POST up to 24 postoperative hours among Group G, Group I and Group GI (P = 0.367, Group G incidence = $34.38 \%$, [95\% confidence interval, 95\% Cl $=17.92-50.83$ ], Group I incidence $=18.75 \%$, $[95 \% \mathrm{Cl}=5.23-32.27]$, Group $\mathrm{Gl}$ incidence $=28.13 \%$, [95\% Cl $=12.55-43.70]$ ). The other outcomes were comparable among the groups.

Conclusions: In patients who had undergone laparoscopic cholecystectomy, gargling with $0.05 \%$ dexamethasone solution demonstrated the same POST prevention effect as intravenous injection of $0.1 \mathrm{mg} / \mathrm{kg}$ dexamethasone. The incidence and severity of POST were not significantly different between the combination of gargling with $0.05 \%$ dexamethasone solution and intravenous injection of $0.1 \mathrm{mg} / \mathrm{kg}$ dexamethasone and use of each of the preventive methods alone.

Keywords: Dexamethasone; Endotracheal intubation; Laparoscopic cholecystectomy; Mouth wash; Postoperative complication; Sore throat.

This is an Open Access article distributed under the terms of the Creative Commons Attribution Non-Commercial License (http://creativecommons.org/licenses/by-nc/4.0) which permits unrestricted non-commercial use, distribution, and reproduction in any medium, provided the original work is properly cited.

Copyright (c) the Korean Society of Anesthesiologists, 2020 


\section{INTRODUCTION}

Postoperative sore throat (POST) is a commonly postoperative complication that occurs in $14.4 \%$ to $73.9 \%$ of patients who undergo general anesthesia with endotracheal intubation [1]. POST may cause patient dissatisfaction and physical discomfort during recovery [2]. Causes of POST are known to be associated with inflammation and stimulation by endotracheal intubation [3]. Various methods have been found effective in reducing POST. The methods that have been reported to be effective in reducing the incidence rate of POST include choice of a smaller endotracheal tube, meticulous manipulation of the laryngoscope, intubation after complete muscle relaxation, minimization of cuff pressure inside the endotracheal tube, smooth suction in the oropharynx, and complete contraction of the endotracheal tube cuff during the postoperative extubation [4].

The pharmacological methods that have been found to be effective in decreasing the incidence and severity of POST include preoperative gargling with ketamine and magnesium solution [5], intravenous injection of dexamethasone [6], and gargling and tube soaking with dexamethasone [7].

Many recent studies have shown that dexamethasone not only prevents postoperative nausea and vomiting but can also relieve pain or reduce general inflammatory responses [8]. The anti-inflammatory and immunosuppressant potency of orally administered dexamethasone is 26.6 times higher than that of cortisol, a natural hormone, and 6.6 times higher than that of prednisone [9]. Dexamethasone is also used to decrease side effects during chemotherapy, treat Addison's disease and adrenal insufficiency, and facilitate fetal lung maturation in pregnant women at high risk of preterm delivery [9].

A previous meta-analysis showed that intravenous dexamethasone decreases the incidence and severity of POST at $1 \mathrm{~h}$ and $24 \mathrm{~h}$ after surgery [10]. Yang et al. [6] and Lee et al. [11] also reported reduced incidence of POST through intravenous injection of dexamethasone.

In the dental field, dexamethasone gargle is used to relieve the symptoms of burning mouth syndrome [12]. Lee et al. [7] reported that gargling with $0.05 \%$ dexamethasone solution decreased the incidence of POST.

No previous studies have been conducted to examine the effect of the combination of dexamethasone gargle and intravenous dexamethasone injection on the incidence and severity of POST. We thought that the incidence of POST differed following administration of the combination of gargling with $0.05 \%$ dexamethasone solution and intravenous injection of $0.1 \mathrm{mg} / \mathrm{kg}$ dexamethasone and use of each of the preventive methods alone. Therefore, the aim of the present study was to investigate the effects of preoperative $\mathbf{0 . 0 5 \%}$ dexamethasone solution gargle, intravenous injection of $0.1 \mathrm{mg} / \mathrm{kg}$ dexamethasone, and combination of the two on the incidence and severity of POST, hoarseness and cough in patients undergoing laparoscopic cholecystectomy.

\section{MATERIALS AND METHODS}

The present study was conducted with patients undergoing elective laparoscopic cholecystectomy. Subjects were 96 patients between the ages of 20-70, and with American Society of Anesthesiologists physical status classification I or II. The duration of anesthesia was between $20 \mathrm{~min}$ and 120 min. Exclusion criteria were modified Mallampati score of 3 or higher; recent throat pain or upper respiratory infection; use of a device stimulating the oral cavity, pharynx or larynx, such as Levin tube or endoscopic nasobiliary drainage; previous experience of POST; contraindications to use of dexamethasone or allergic response to it. Additionally, cases in which intubation was attempted three times or more, in which endotracheal intubation was performed using a stylet, in which the Cormack-Lehane grade was 3 or higher were excluded.

This study was approved by the Institutional Review Board as a prospective, randomized, double-blind study (no. 190032), and registered with the Clinical Research Information Service (https://cris.nih.go.kr, no. KCT0004971). In the study, the patients were sufficiently informed and asked to sign a written consent prior to surgery. The patients were randomly allocated, using a computer-generated random number table, to three groups, Gargle group (Group G, n = 32), IV group (Group I, $\mathrm{n}=32$ ), and Gargle + IV group (Group GI, $\mathrm{n}=32$ ), at a ratio of 1:1:1. To blind the group allocation, the pharmacist was given a sealed envelope with a coding number written on it and asked to prepare syringes for drug injection and containers of the gargle solution. The syringes for drug injection contained either $0.9 \%$ normal saline solution $2 \mathrm{ml}$ or mixed solution $2 \mathrm{ml}$ (dexamethasone $0.1 \mathrm{mg} / \mathrm{kg}+0.9 \%$ normal saline). The containers of the gargle solution contained either $0.9 \%$ normal saline 10 $\mathrm{ml}$ or $0.05 \%$ dexamethasone solution $10 \mathrm{ml}$ (dexamethasone $5 \mathrm{mg} / \mathrm{ml}+0.9 \%$ normal saline $9 \mathrm{ml}$ ) prepared asepti- 
cally and passed on to the anesthesiologist on the day of surgery. In all procedures requiring the use of a syringe (Bandgold filter syringe $^{\mathrm{\tau M}}$, Bandgold Co., Korea), a filter system was used to prevent the inflow of tiny impurities into the body. An anesthesiologist who was unaware of the group allocation, administered the drugs to the patients according to the coding number, after which anesthetic induction, endotracheal intubation and extubation were performed. After the surgery, another anesthesiologist, not the one who performed the anesthesia for the surgery, visited the patients in the ward to conduct the medical examination through an interview.

A total of 96 patients were allocated to the three groups. The patients in the gargle group (Group G) were treated with $0.05 \%$ dexamethasone solution gargle for $30 \mathrm{~s}$ at 10 min before general anesthesia by sufficiently tilting the head backward, followed by intravenous injection of $2 \mathrm{ml}$ of $0.9 \%$ normal saline solution $5 \mathrm{~min}$ before general anesthesia. The patients in the intravenous injection group (Group I) were treated with $0.9 \%$ normal saline solution gargle for $30 \mathrm{~s}$ at $10 \mathrm{~min}$ before general anesthesia by sufficiently tilting the head backward, followed by intravenous injection of $0.1 \mathrm{mg} / \mathrm{kg}$ dexamethasone, mixed with $0.9 \%$ normal saline solution in a resulting volume of $2 \mathrm{ml}, 5 \mathrm{~min}$ before general anesthesia. The patients in the gargle + intravenous injection group (Group GI) were treated with
0.05\% dexamethasone solution gargle for $30 \mathrm{~s}$ at $10 \mathrm{~min}$ before general anesthesia by sufficiently tilting the head backward, followed by intravenous injection of $0.1 \mathrm{mg} / \mathrm{kg}$ dexamethasone, mixed with $0.9 \%$ normal saline solution in a resulting volume of $2 \mathrm{ml}, 5 \mathrm{~min}$ before general anesthesia (Fig. 1).

The patients were intramuscularly injected, as premedication $30 \mathrm{~min}$ before the surgery, with glycopyrrolate 0.2 $\mathrm{mg}$ and famotidine $20 \mathrm{mg}$. Propofol (2 mg/kg) and lidocaine $(1 \mathrm{mg} / \mathrm{kg}$ ) were used for induction of anesthesia. Rocuronium $(0.6 \mathrm{mg} / \mathrm{kg})$ was used as a neuromuscular blocker. Endotracheal intubation was performed after verifying that the bispectral index (BIS VISTA ${ }^{\mathrm{TM}}$ Monitoring System, Covidien, Boulder, USA) was below 60 and the train-of-four TOF (TOF-Watch SX ${ }^{\circledR}$, Organon Ltd., Ireland) count was 0 (zero) following injection of the neuromuscular blocker. The Cormack grade of all patients included in the statistical analysis was 1, and endotracheal intubation was successfully performed in two or fewer attempts in all of them. In the case of tracheal intubation in men, Macintosh \# 3.5 (Briteblade pro ${ }^{\mathrm{TM}}$, Flexicare medical, USA) was used for laryngoscope and \# 3 in women, and stylet was not used. The inner diameter of the silicon tube of the laryngoscope used for the endotracheal intubation was $7.5 \mathrm{~mm}$ (Sheridan/ $\mathrm{CF}^{\circledR}$, Teleflex Medical, USA) for the male subjects and 7.0 $\mathrm{mm}$ for the female subjects. An oral airway (Ace Grip Endo

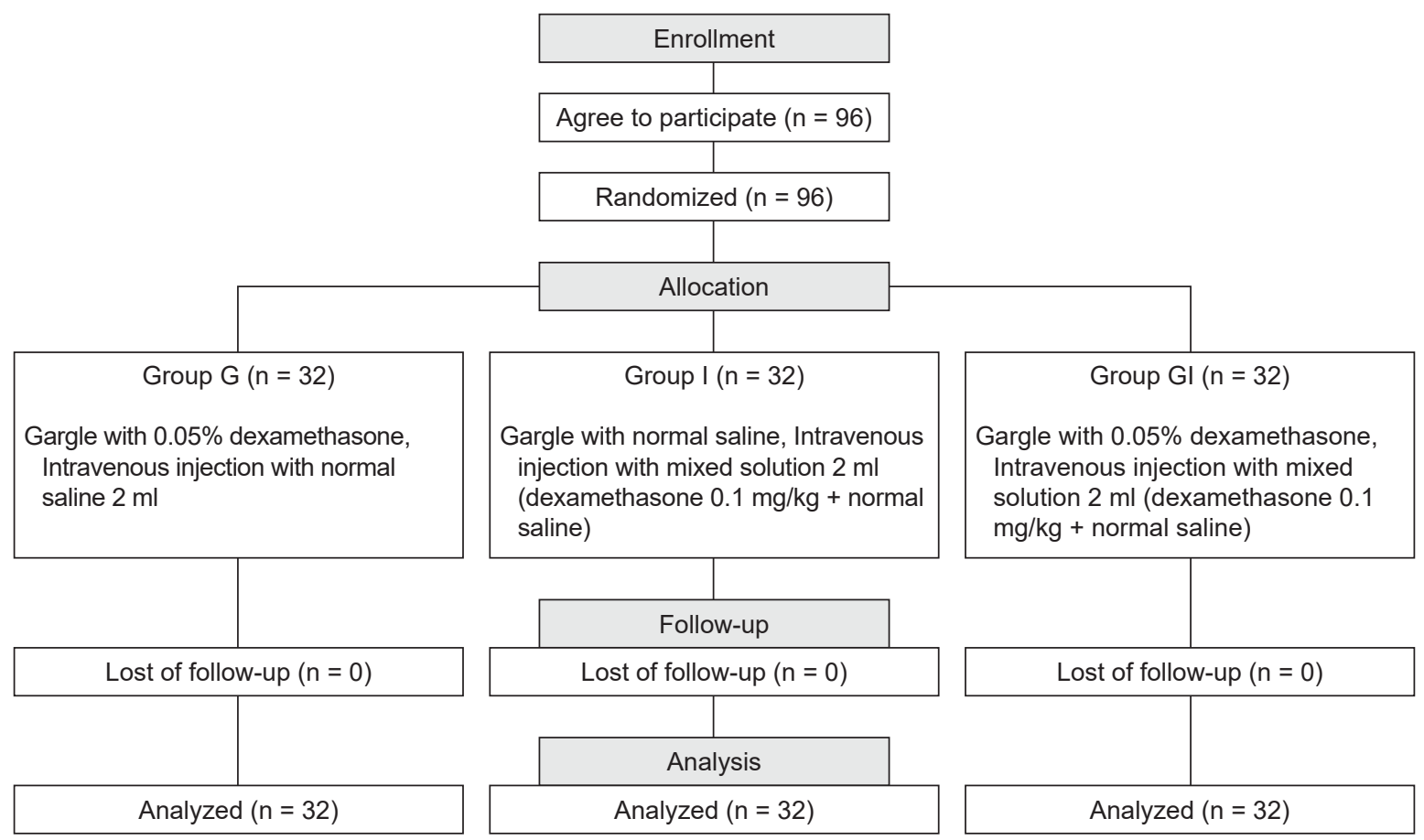

Fig. 1. Flow diagram of study enrollment. 
Fix $^{\mathrm{TM}}$, Ace Medical Co. Ltd., Korea) was fixed with an endotracheal tube in all study patients. Anesthesia was maintained using sevoflurane 1.5 to 2.5 vol\%, $50 \% \mathrm{O}_{2}$ with air, and remifentanil $0.05-0.1 \mu \mathrm{g} / \mathrm{kg} / \mathrm{min}$. The nasopharyngeal temperature, electrocardiogram, oxygen saturation, and capnogram were monitored, and an airway without the heating and humidifying functions was used. At the start and end of the surgery, a cuff pressure gauge (Mallinckrodt $^{\mathrm{TM}}$ Hand Pressure Gauge, Covidien Deutschland GmbH, Germany) was used to keep the pressure at 20 to $30 \mathrm{~cm}$ $\mathrm{H}_{2} \mathrm{O}$. Ten minutes before the end of the surgery, tramadol 0.5 to $1 \mathrm{mg} / \mathrm{kg}$ and ramosetron $0.3 \mathrm{mg}$ were intravenously injected to prevent postoperative pain, nausea and vomiting. After the end of the surgery, no endotracheal suction was performed but oral suction was lightly performed. Sugammadex (2-4 mg/kg) was administered to reverse the neuromuscular blocker. Extubation was carried out gently after verifying that the TOF ratio was 0.9 or higher, monitoring the patients' recovery of consciousness, and following the anesthesiologist's orders.

An interview regarding POST was conducted with the patients within $24 \mathrm{~h}$ after the surgery, considering that an acute inflammatory response usually reaches its peak in about $24 \mathrm{~h}$ and the incidence of POST is decreased within $24 \mathrm{~h}$ when dexamethasone is used [11]. In each group, an anesthesiologist who was unaware of the allocation of the patients to the groups visited the ward at 1, 6, and $24 \mathrm{~h}$ after the surgery to interview the patients about sore throat, hoarseness and cough. The severity of POST, hoarseness and cough was evaluated on a four-point scale (Table 1)

Table 1. Scoring System for Sore Throat, Cough and Hoarseness [13]

\begin{tabular}{cl}
\hline Severity score & \\
\hline Sore throat & \\
0 & No sore throat \\
1 & Minimal sore throat \\
2 & Moderate sore throat \\
3 & Severe sore throat \\
Cough & \\
0 & No cough \\
1 & Minimal cough \\
2 & Moderate cough \\
3 & Severe cough \\
Hoarseness & \\
0 & No hoarseness \\
1 & Hoarseness at the time of interview, but noted only \\
2 & by patient \\
3 & Hoarseness that is readily apparent, but mild \\
\hline
\end{tabular}

[13]. POST was defined as discomfort at the larynx or pharynx, while resting or swallowing the saliva after the surgery [6]. The responses were categorized into cases of no sore throat (no sore throat, 0 ), cases in which throat pain could be felt by the patient only when the patient was asked about the presence of sore throat (minimal sore throat, 1), cases in which the patient himself or herself complained about sore throat (moderate sore throat, 2), and cases in which the patient obviously felt discomfort due to sore throat (severe sore throat, 3). Hoarseness and cough were also evaluated using the same method [13]. Patients with minimal symptoms or more (1 point or more in four-point scale) were included in incidence data estimates. Visual analog scale (VAS) scores of wound pain were recorded at the same time points. Additionally, other side effects in addition to POST were identified and specifically recorded.

To control postoperative abdominal pain, when the VAS was 5 or higher in the PACU, ketorolac tromethamine $30 \mathrm{mg} /$ $\mathrm{ml}$ was administered and acetaminophen $1 \mathrm{~g} / 100 \mathrm{ml}$ was intravenously injected three times a day in the ward. When the VAS score of the pain at the surgical site was 5 or higher, intravenous injection of tramadol $0.5 \mathrm{mg} / \mathrm{kg}$ was additionally performed to control the surgical pain. If the pain continued at a VAS score of 5 or higher despite the pain control, nalbuphine 2.5 mg was intravenously injected.

The primary outcome measure was the incidence of POST. The secondary outcome measures were the incidence of hoarseness and cough, and the severity of POST, hoarseness and cough.

Considering that the incidence of POST in the group that received prophylactic dexamethasone intravenous injection was 0.69 in the study by Park et al. [13], that the POST incidence in the dexamethasone gargle group was 0.33 in Lee et al. [7], and that the POST incidence in the Gargle + IV Group would be lower than 0.33 , the necessary number of subjects in each group was calculated to be 29 with a significance level of 0.05 and power of $80 \%$. To adjust a familywise error rate, we applied $Z_{\frac{\alpha}{2} / 3}$ in sample size calculation. Taking into consideration the $10 \%$ dropout rate, the number of subjects in each group was determined to be 32 .

Data was presented as mean \pm SD for continuous variables, and count and percentage for categorical variables. Age, American Society of Anesthesiologists physical status classification, height, weight, anesthesia time, initial time cuff pressure, end time cuff pressure, dose of drugs administered (remifentanil, tramadol, sugammadex, acetaminophen for postoperative wound pain) and wound pain VAS 
were compared among treatment groups using analysis of variance or Kruskal-Wallis test as appropriate. The incidence of pain, hoarseness and cough were analyzed with chi-square test. To adjust a type I error rate, we recalculated the level of significance by applying the Bonferroni method (i.e., $\left.\mathrm{P}\left(\chi^{2}>5.73\right)=0.05 / 3=0.0167\right)$. SAS macro for nonparametric analysis of factorial longitudinal data in Brunner et al. [14] was performed to compare the scores from three groups, repeated measures. Statistical analysis was conducted using SAS 9.4 (SAS Institute Inc., USA). A P less than 0.05 was considered as statistically significant.

\section{RESULTS}

From September 2019 to April 2020, 96 patients were screened and enrolled in the study. These patients were randomly allocated to three groups. The evaluation was performed with the 96 patients who satisfied the inclusion criteria, and all patients completed the study with no dropouts. No significant differences were found in the sex ratio, age, anesthesia time, American Society of Anesthesiologists physical status classification, height, weight, initial time endotracheal tube cuff pressure and end time endotracheal tube cuff pressure. The total doses of drugs administered (remifentanil, tramadol, and sugammadex in the perioperative period, acetaminophen for postoperative pain control) and wound pain VAS scores were comparable among Group G, Group I, and Group GI (Table 2).

The sore throat incidence and severity over time did not show a significant difference among Group G, Group I, and Group GI at $1 \mathrm{~h}, 6 \mathrm{~h}$ and $24 \mathrm{~h}$ in resting and swallowing (Table 3, resting POST group * time $\mathrm{P}=0.558$, swallowing POST group * time $\mathrm{P}=0.751$, total POST incidence $\mathrm{P}=0.367$, group $\mathrm{G}$ incidence $=34.38 \%$, [95\% confidence interval, $95 \% \mathrm{CI}=17.92-50.83]$, group $\mathrm{I}$ incidence $=18.75 \%,[95 \%$ $\mathrm{CI}=5.23-32.27]$, group GI incidence $=28.13 \%$, $[95 \% \mathrm{CI}=$ 12.55-43.70]).

The hoarseness incidence and severity did not show a significant difference among the groups at $1 \mathrm{~h}, 6 \mathrm{~h}$ and $24 \mathrm{~h}$ after the surgery (Table 4 , hoarseness group * time $\mathrm{P}=$ 0.654 , total hoarseness incidence $\mathrm{P}=0.415$, group $\mathrm{G}$ incidence $=62.50 \%$, [95\% CI $=45.73-79.27]$, group I incidence $=46.88 \%$, $[95 \% \mathrm{CI}=29.58-64.17]$, group GI incidence $=$ $50.00 \%$, [95\% CI $=32.68-67.32]$ ). The cough incidence and

Table 2. Patient Characteristics, Perioperative and Postoperative Data

\begin{tabular}{|c|c|c|c|c|}
\hline Variable & Group $\mathrm{G}(\mathrm{n}=32)$ & Group I $(n=32)$ & Group $\mathrm{Gl}(\mathrm{n}=32)$ & $P$ value \\
\hline Sex & & & & 0.840 \\
\hline M & $14(44)$ & $12(38)$ & $12(38)$ & \\
\hline $\mathrm{F}$ & $18(56)$ & $20(62)$ & $20(62)$ & \\
\hline Age (yr) & $46.9 \pm 12.6$ & $48.8 \pm 13.1$ & $47.0 \pm 14.5$ & 0.780 \\
\hline ASA & & & & 0.287 \\
\hline I & $21(66)$ & $24(75)$ & $18(56)$ & \\
\hline II & $11(34)$ & $8(25)$ & $14(44)$ & \\
\hline Height (cm) & $165.0 \pm 8.3$ & $162.8 \pm 7.8$ & $162.4 \pm 9.7$ & 0.339 \\
\hline Weight (kg) & $68.0 \pm 10.6$ & $65.1 \pm 11.5$ & $65.3 \pm 13.0$ & 0.380 \\
\hline Anesthesia time (min) & $51.3 \pm 10$ & $53.6 \pm 13.8$ & $52.8 \pm 10.0$ & 0.708 \\
\hline Initial time cuff pressure $\left(\mathrm{cmH}_{2} \mathrm{O}\right)$ & $27.9 \pm 0.6$ & $27.9 \pm 0.6$ & $28.0 \pm 0.7$ & 0.835 \\
\hline End time cuff pressure $\left(\mathrm{cmH}_{2} \mathrm{O}\right)$ & $27.2 \pm 0.8$ & $27.3 \pm 0.6$ & $27.4 \pm 0.8$ & 0.608 \\
\hline Dose of remifentanil administered $(\mu \mathrm{g})$ & $195.3 \pm 63.5$ & $201.2 \pm 77.8$ & $199.5 \pm 87.6$ & 0.902 \\
\hline Dose of tramadol administered (mg) & $47.8 \pm 4.2$ & $46.9 \pm 4.7$ & $45.9 \pm 5.0$ & 0.274 \\
\hline Dose of sugammadex administered (mg) & $192.2 \pm 18.5$ & $184.4 \pm 23.6$ & $190.63 \pm 19.8$ & 0.282 \\
\hline Dose of acetaminophen administered (g) & $2.8 \pm 0.4$ & $28.9 \pm 0.4$ & $2.8 \pm 0.37$ & 0.932 \\
\hline \multicolumn{5}{|l|}{ Wound pain VAS $(0-10)$} \\
\hline $1 \mathrm{~h}$ & $3(2,3)$ & $2(2,3)$ & $3(2,3)$ & 0.951 \\
\hline $6 \mathrm{~h}$ & $3(2,3)$ & $2(2,3)$ & $3(2,3)$ & 0.959 \\
\hline $24 \mathrm{~h}$ & $3(2,3)$ & $2(2,3)$ & $3(2,3)$ & 0.880 \\
\hline
\end{tabular}

Data presented as number of patients, mean \pm SD, or median (1Q, 3Q). Group G: gargle with $0.05 \%$ dexamethasone solution, intravenous injection with $0.9 \%$ normal saline $2 \mathrm{ml}$, Group l: gargle with $0.9 \%$ normal saline, intravenous injection with mixed solution $2 \mathrm{ml}$ (dexamethasone $0.1 \mathrm{mg} / \mathrm{kg}+0.9 \%$ normal saline), Group Gl: gargle with $0.05 \%$ dexamethasone solution, intravenous injection with mixed solution 2 ml (dexamethasone $0.1 \mathrm{mg} / \mathrm{kg}+0.9 \%$ normal saline). ASA: American Society of Anesthesiologists physical status classification, VAS: Visual Analog Scale. 
Table 3. Incidence and Severity of Sore Throat among the Groups after Tracheal Extubation

\begin{tabular}{|c|c|c|c|c|c|c|c|}
\hline \multirow{2}{*}{\multicolumn{2}{|c|}{ Post operation time (severity score) }} & \multirow{2}{*}{ Group $G(n=32)$} & \multirow{2}{*}{ Group I ( $n=32)$} & \multirow{2}{*}{ Group GI ( $\mathrm{n}=32)$} & \multicolumn{3}{|c|}{$P$ value } \\
\hline & & & & & Group & Time & Group * time \\
\hline \multirow[t]{3}{*}{ Resting } & $1 \mathrm{~h}(0 / 1 / 2 / 3)$ & $26 / 6 / 0 / 0$ & $29 / 3 / 0 / 0$ & $29 / 3 / 0 / 0$ & 0.258 & 0.006 & 0.558 \\
\hline & $6 \mathrm{~h}(0 / 1 / 2 / 3)$ & $30 / 2 / 0 / 0$ & $30 / 2 / 0 / 0$ & $32 / 0 / 0 / 0$ & & & \\
\hline & $24 \mathrm{~h}(0 / 1 / 2 / 3)$ & $31 / 1 / 0 / 0$ & $32 / 0 / 0 / 0$ & $32 / 0 / 0 / 0$ & & & \\
\hline \multirow[t]{3}{*}{ Swallowing } & $1 \mathrm{~h}(0 / 1 / 2 / 3)$ & $26 / 6 / 0 / 0$ & $28 / 4 / 0 / 0$ & $28 / 4 / 0 / 0$ & 0.203 & 0.000 & 0.751 \\
\hline & $6 \mathrm{~h}(0 / 1 / 2 / 3)$ & $23 / 9 / 0 / 0$ & $24 / 8 / 0 / 0$ & $28 / 4 / 0 / 0$ & & & \\
\hline & $24 \mathrm{~h}(0 / 1 / 2 / 3)$ & $29 / 3 / 0 / 0$ & $30 / 2 / 0 / 0$ & $32 / 0 / 0 / 0$ & & & \\
\hline \multicolumn{2}{|c|}{$\begin{array}{l}\text { Total incidence (95\% confidence inter- } \\
\text { val) }\end{array}$} & $34.38 \%(17.92-50.83)$ & $18.75 \%(5.23-32.27)$ & $28.13 \%(12.55-43.70)$ & & 0.367 & \\
\hline
\end{tabular}

Data are presented as number of patients. Severity of sore throat was assessed using 4 scoring system: 0 , no sore throat; 1 , mild sore throat; 2 , moderate sore throat; 3 , severe sore throat. The statistical significance was accepted with $\mathrm{P}$ values less than 0.05 for primary comparison among groups.

Table 4. Incidence and Severity of Hoarseness among the Groups after Tracheal Extubation

\begin{tabular}{|c|c|c|c|c|c|c|}
\hline \multirow{2}{*}{ Post operation time (severity score) } & \multirow{2}{*}{ Group $\mathrm{G}(\mathrm{n}=32)$} & \multirow{2}{*}{ Group I ( $n=32)$} & \multirow{2}{*}{ Group GI ( $n=32)$} & \multicolumn{3}{|c|}{$P$ value } \\
\hline & & & & Group & Time & Group * time \\
\hline $1 \mathrm{~h}(0 / 1 / 2 / 3)$ & $15 / 17 / 0 / 0$ & $20 / 12 / 0 / 0$ & $24 / 8 / 0 / 0$ & 0.062 & 0.000 & 0.654 \\
\hline $6 \mathrm{~h}(0 / 1 / 2 / 3)$ & $19 / 13 / 0 / 0$ & $24 / 8 / 0 / 0$ & $23 / 9 / 0 / 0$ & & & \\
\hline $24 \mathrm{~h}(0 / 1 / 2 / 3)$ & $26 / 6 / 0 / 0$ & $31 / 1 / 0 / 0$ & $30 / 2 / 0 / 0$ & & & \\
\hline Total incidence (95\% confidence interval) & $62.5 \%(45.73-79.27)$ & $46.88 \%(29.58-64.17)$ & $50 \%(32.68-67.32)$ & & 0.4 & \\
\hline
\end{tabular}

Data are presented as number of patients. Severity of hoarseness was assessed using 4 scoring system: 0, no hoarseness; 1 , mild hoarseness; 2, moderate hoarseness; 3 , severe hoarseness. The statistical significance was accepted with P values less than 0.05 for primary comparison among groups.

Table 5. Incidence and Severity of Cough among the Groups after Tracheal Extubation

\begin{tabular}{|c|c|c|c|c|c|c|}
\hline \multirow{2}{*}{ Post operation time (severity score) } & \multirow{2}{*}{ Group G (n = 32) } & \multirow{2}{*}{ Group I $(n=32)$} & \multirow{2}{*}{ Group GI ( $\mathrm{n}=32$ ) } & \multicolumn{3}{|c|}{$P$ value } \\
\hline & & & & Group & Time & Group * time \\
\hline $1 \mathrm{~h}(0 / 1 / 2 / 3)$ & $32 / 0 / 0 / 0$ & $30 / 2 / 0 / 0$ & $31 / 1 / 0 / 0$ & 0.141 & 0.157 & 0.388 \\
\hline $6 \mathrm{~h}(0 / 1 / 2 / 3)$ & $32 / 0 / 0 / 0$ & $31 / 1 / 0 / 0$ & $31 / 1 / 0 / 0$ & & & \\
\hline $24 \mathrm{~h}(0 / 1 / 2 / 3)$ & $32 / 0 / 0 / 0$ & $32 / 0 / 0 / 0$ & $30 / 2 / 0 / 0$ & & & \\
\hline Total incidence (95\% confidence interval) & $0.00 \%$ & $6.25 \%(0.00-14.64)$ & $6.25 \%(0.00-14.64)$ & & 0.54 & \\
\hline
\end{tabular}

Data are presented as number of patients. Severity of cough was assessed using 4 scoring system: 0, no cough; 1 , mild cough; 2 , moderate cough; 3 , severe cough. The statistical significance was accepted with $\mathrm{P}$ values less than 0.05 for primary comparison among groups.

severity did not show a significant difference among the groups at $1 \mathrm{~h}, 6 \mathrm{~h}$ and $24 \mathrm{~h}$ after the surgery (Table 5, cough group * time $\mathrm{P}=0.388$, total hoarseness incidence $\mathrm{P}=$ 0.541 , group $\mathrm{G}$ incidence $=0.00 \%$, group I incidence $=$ $6.25 \%$, $[95 \% \mathrm{CI}=0.00-14.64]$, group GI incidence $=6.25 \%$, $[95 \% \mathrm{CI}=0.00-14.64])$.

No postoperative complication, except sore throat, cough and hoarseness, was found in any of the patients in the three groups.

\section{DISCUSSION}

We predicted that combined gargle and intravenous injection of dexamethasone would lead to a lower incidence of POST than use of each of the preventive methods alone, but our findings revealed no difference between the combined or single applications with respect to POST.

According to the experimental results of the present study, the POST-preventing effect of gargling with $0.05 \%$ dexamethasone solution alone and that of intravenous injection of $0.1 \mathrm{mg} / \mathrm{kg}$ dexamethasone solution alone were equivalent to the effect of the combination of gargling with 0.05\% dexamethasone solution and subsequent intravenous injection of $0.1 \mathrm{mg} / \mathrm{kg}$ dexamethasone.

The combined gargle and intravenous injection of dexamethasone did not demonstrate a better POST-preventing effect than the single use of each method, probably because the topical application of dexamethasone gargle did not result in any increase in the plasma drug concentration over that caused by the intravenous injection. 
De Oliveira et al. [15] reported that the incidence and severity of POST showed a decrease when dexamethasone $0.1 \mathrm{mg} / \mathrm{kg}$ was administered intravenously than when dexamethasone $0.05 \mathrm{mg} / \mathrm{kg}$ was administered by the same method. Park et al. [2] reported that the intravenous injection of dexamethasone $0.2 \mathrm{mg} / \mathrm{kg}$ was more effective in reducing the incidence and severity of POST than the intravenous injection of dexamethasone $0.1 \mathrm{mg} / \mathrm{kg}$. The explanation for these findings may be that the plasma drug concentration was increased as the dose of dexamethasone administered by intravenous injection was increased. Gargling with dexamethasone did not increase the effect, because it may have not increased the plasma drug concentration. Therefore, we suspect that the combination of gargling with $0.05 \%$ dexamethasone solution and intravenous injection of $0.1 \mathrm{mg} / \mathrm{kg}$ dexamethasone did not increase the concentration of dexamethasone in the blood, resulting in no better effect on incidence of POST.

The incidence of POST was investigated at $1 \mathrm{~h}, 6 \mathrm{~h}$, and $24 \mathrm{~h}$ postoperatively because the complaint of pain within one hour after the surgery may be decreased by the analgesic used for the general anesthesia [3]. As reported by Hung et al. [3], the incidence of POST was highest at $6 \mathrm{~h}$ postoperative.

In the present study, among the patients who received dexamethasone $0.1 \mathrm{mg} / \mathrm{kg}$ intravenous injection, the proportion of those who complained of sore throat during swallowing was $12 \%$ at $1 \mathrm{~h}$ after the surgery, $25 \%$ at $6 \mathrm{~h}$ after the surgery, and $6 \%$ at $24 \mathrm{~h}$ after the surgery. Lee et al. [11] reported that among the patients in their study who were intravenously injected with dexamethasone $0.1 \mathrm{mg} / \mathrm{kg}$, the proportion of those who complained of throat pain was $40 \%$ at $1 \mathrm{~h}$ after the surgery, $17 \%$ at $6 \mathrm{~h}$ after the surgery, and $4 \%$ at $24 \mathrm{~h}$ after the surgery. The difference between the two studies may be the result of the change in the patient's position required for the lumbar spine surgery in the study by Lee et al. [11]; that change may have resulted in a change in the endotracheal tube cuff pressure and an abnormality in the tube location [16].

POST is caused by endotracheal intubation, which results in a mucosal injury or vocal cord injury in the trachea [17]. The intubation to the posterior pharynx, larynx and airway, the expansion of the cuff, and the direct manipulation of the laryngoscope cause the stimulation and inflammation [6].

Various interventions have been attempted to reduce the incidence of POST but none of them was capable of com- pletely removing the complication. Steroid has been often used to prevent sore throat, and systemic dexamethasone is the most widely studied drug for POST [18]. A wide spectrum of methods may be used for the delivery of steroid, such as soaking the endotracheal tube with triamcinolone [19], gargling with dexamethasone or soaking a endotracheal tube in it [7], or intravenously injecting dexamethasone [6]. Intravenous injection of dexamethasone showed significant effect on the prevention of postoperative nausea and vomiting [20], and intraperitoneal administration of dexamethasone showed a significantly greater decrease in nausea in comparison with the intravenous injection [21].

Corticosteroid binds to annexin proteins and thus generates $\mathrm{Ca}^{2+}$-dependent phospholipids to inhibit phospholipase $\mathrm{A}_{2}$ and decrease the synthesis of inflammatory mediator, prostaglandins, and leukotriene [22]. In addition, corticosteroid suppresses the transport of leukocytes to inflammatory sites, inhibits the release of cytokine by maintaining cellular integrity, and causes anti-inflammatory responses by inhibiting the growth of fibroblasts [23].

Local use of dexamethasone for the reduction of postoperative pain includes its addition in ultrasound-guided transverse abdominis plane block [24] and oral gargling [7]. In the patient undergoing unilateral inguinal hernia repair, the addition of dexamethasone during ultrasound-guided transverse abdominis plane block decreased the numerical rating scale score more than the administration of levobupivacaine alone [24].

Dexamethasone gargle was effective on the oral mucosa to prevent POST [7]. Gargling for prevention of postoperative sore throat showed an effect on the local nociceptors rather than a systemic effect [5]. In the present study, the total incidence of POST within $24 \mathrm{~h}$ of dexamethasone $\mathbf{0 . 0 5 \%}$ gargle was $34.4 \%$, similar to the findings of Lee et al. [7] that the total incidence within $24 \mathrm{~h}$ of dexamethasone $\mathbf{0 . 0 5 \%}$ gargle was $33.3 \%$. The oral mucosa has a thin horny layer and many blood vessels and is capable of allowing a larger amount of drug to reach vessels, compared to the skin. Drugs that can be administered through application are selected in oral mucosal diseases because they can penetrate into the level of the basement membrane and remain effective for a longer period in comparison with intravenous drug administration [25]. There is no commercially available dexamethasone gargle solution product in Korea. However, solutions at a concentration of $0.01 \%$ to $\mathbf{0 . 0 6 \%}$ are prepared by mixing dexamethasone powder or liquid with normal saline solution or distilled water, and 
used for patients in the departments of otolaryngology, dentistry, and hemato-oncology (burning mouth syndrome, oral lichen planus, intraoral ulcer) [26]. In the present study, as in that reported by Lee et al. [7], dexamethasone $5 \mathrm{mg} / \mathrm{ml}$ was mixed with normal saline $9 \mathrm{ml}$ to prepare a $0.05 \%$ solution, which was used for gargling for $30 \mathrm{~s}$ with the head sufficiently tilted backward.

Dexamethasone gargle is considered to allow the drug to function directly on the mucosa of the pharynx and larynx where POST is caused. Gargling with dexamethasone has advantages because it can be simply performed before a elective surgery and its effect is observed within several minutes [27]. According to Park et al. [26], patients who received dexamethasone gargle to treat oral manifestations of chronic graft versus host disease (cGVHD) had decreased cGVHD severity and pain scores.

In the present study, the incidence of POST during swallowing in patients treated with the combination of $0.05 \%$ dexamethasone solution gargle and intravenous injection of dexamethasone $0.1 \mathrm{mg} / \mathrm{kg}$ was $13 \%$ at $1 \mathrm{~h}, 13 \%$ at $6 \mathrm{~h}$, and $0 \%$ at $24 \mathrm{~h}$ postoperatively, indicating that the POST-preventing effect of the combination was not significantly different from the use of either dexamethasone gargle or dexamethasone intravenous injection alone. This finding indicates that the topical application of dexamethasone gargle has an effect equivalent to that of dexamethasone intravenous injection, and suggests that the combination of the two administration methods does not provide a superior outcome in the prevention of POST.

As mentioned at the beginning of the discussion, we think that the combined use of dexamethasone gargle and intravenous injection did not increase the concentration of dexamethasone in the blood, resulting in no better effect on incidence of POST.

In this experiment, using only dexamethasone did not bring a better effect on incidence of POST, in contrast, the combination of dexamethasone with other drugs was found more effective in reducing POST than the use of a single drug. Safavi et al. [28] reported that incidence of POST at postoperative $0 \mathrm{~h}, 2 \mathrm{~h}, 4 \mathrm{~h}, 8 \mathrm{~h}$ and $24 \mathrm{~h}$ was lower in the group in which gargling with a $30 \mathrm{ml}$ solution containing $40 \mathrm{mg}$ ketamine was used in combination with intravenous injection of dexamethasone $0.2 \mathrm{mg} / \mathrm{kg}$ than in the other two groups in which only one of the two methods was used. The combination of intravenous injection of dexamethasone and ketamine gargle reduced the incidence of POST in comparison with the single use of each administration method. This result may be due to a synergic effect caused by the anti-hyperalgesic effect of ketamine and the anti-inflammatory effect of dexamethasone [28]. According to Cho et al. [29], the incidence of POST within 24 postoperative hours was lower in the group that received dexamethasone $8 \mathrm{mg} / \mathrm{kg}$ intravenous injection in combination with lidocaine $1.5 \mathrm{mg} / \mathrm{kg}$ than in the group that received only dexamethasone $8 \mathrm{mg} / \mathrm{kg}$ intravenous injection. In this case, a synergic effect might have been the result of the suppression of the airway reflex, reduced bronchial hyper-reactivity, and pain relief caused by lidocaine, and the anti-inflammatory effect of dexamethasone [29].

Therefore, the use of drugs with different mechanisms seems to be more effective than use of a single drug in the prevention of POST.

The present study has the following limitations.

First, the plasma dexamethasone concentration was not measured in the cases of dexamethasone intravenous injection, dexamethasone gargle, and their combination. Even the use of a single dose of steroid has the risk of increasing postoperative infection, hemorrhage and inflammation [30]. Although such problems did not occur within 24 postoperative hours in the present study, the possibility of systemic side effects thereafter was not predicted. Second, the incidence and severity of POST were investigated in the present study by applying the dexamethasone administration methods only to patients undergoing laparoscopic cholecystectomy, which requires a relatively short surgical time. In comparison with laparotomy, the incidence of POST may be higher in patients undergoing laparoscopic surgery because the cuff pressure of the endotracheal tube is higher owing to pneumoperitoneum and the Trendelenburg position. Since the duration of anesthesia for the laparoscopic cholecystectomy in the present study was about $50 \mathrm{~min}$, further studies may need to be conducted to investigate the incidence and severity of POST in cases in which the surgical duration is longer. Third, the dose of dexamethasone for the intravenous injection was 0.1 $\mathrm{mg} / \mathrm{kg}$ in the present study. The dose of the dexamethasone for the intravenous injection, tested with respect to POST, was fixed or varied on the basis of the weight (0.1-0.2 $\mathrm{mg} / \mathrm{kg}$ ). Further studies may need to be conducted on the POST-preventing effect of dexamethasone depending on the dose $[10,18]$. Fourth, the evaluation of POST, hoarseness and cough was performed in the present study based on patient's subjective responses obtained through inter- 
view. Therefore, the individual patients might have expressed their symptoms differently depending on their experiences and psychological state.

In conclusion, in the patients who had undergone laparoscopic cholecystectomy, gargling with $0.05 \%$ dexamethasone solution showed the same POST-preventing effect as the intravenous injection of $0.1 \mathrm{mg} / \mathrm{kg}$ dexamethasone. The incidence and severity of POST were not significantly different between the combination of $0.05 \%$ dexamethasone solution gargle and $0.1 \mathrm{mg} / \mathrm{kg}$ dexamethasone intravenous injection and the use of each of the two preventive methods alone.

\section{CONFLICTS OF INTEREST}

No potential conflict of interest relevant to this article was reported.

\section{AUTHOR CONTRIBUTIONS}

Conceptualization: Seunghee Ki, Jeonghan Lee. Data curation: Inwook Myoung, Kwanghee Kim. Formal analysis: Sehun Lim, Kwangrae Cho, Yongjae Han, Minkyung Oh, Yohan Park. Methodology: Seunghee Ki, Sehun Lim, Yohan Park. Project administration: Soonho Cheong, Kwangrae Cho, Yohan Park, Kwanghee Kim. Visualization: Myounghun Kim, Yongjae Han. Writing - original draft: Seunghee Ki, Inwook Myoung, Yongjae Han, Jeonghan Lee. Writing - review \& editing: Seunghee Ki, Soonho Cheong, Jeonghan Lee. Investigation: Inwook Myoung, Kwangrae Cho, Myoung-hun Kim, Minkyung Oh, Yohan Park. Resources: Inwook Myoung, Kwangrae Cho, Myoung-hun Kim, Yongjae Han, Minkyung Oh, Yohan Park, Kwanghee Kim. Software: Myoung-hun Kim, Minkyung Oh. Supervision: Seunghee Ki, Soonho Cheong, Sehun Lim. Validation: Soonho Cheong, Sehun Lim, Minkyung Oh.

\section{ORCID}

Seunghee Ki, https://orcid.org/0000-0002-1792-3771 Inwook Myoung, https://orcid.org/0000-0003-0001-3306 Soonho Cheong, https://orcid.org/0000-0002-9368-6026 Sehun Lim, https://orcid.org/0000-0001-8450-0595 Kwangrae Cho, https://orcid.org/0000-0002-9805-9582 Myoung-hun Kim, https://orcid.org/0000-0002-4350-0078 Yongjae Han, https://orcid.org/0000-0001-7321-1376 Minkyung Oh, https://orcid.org/0000-0001-7584-5436
Yohan Park, https://orcid.org/0000-0002-2242-0968

Kwanghee Kim, https://orcid.org/0000-0003-2013-0788

Jeonghan Lee, https://orcid.org/0000-0002-4616-0355

\section{REFERENCES}

1. Xu YJ, Wang SL, Ren Y, Zhu Y, Tan ZM. A smaller endotracheal tube combined with intravenous lidocaine decreases post-operative sore throat - a randomized controlled trial. Acta Anaesthesiol Scand 2012; 56: 1314-20.

2. Park SH, Han SH, Do SH, Kim JW, Rhee KY, Kim JH. Prophylactic dexamethasone decreases the incidence of sore throat and hoarseness after tracheal extubation with a double-lumen endobronchial tube. Anesth Analg 2008; 107: 1814-8.

3. Hung NK, Wu CT, Chan SM, Lu CH, Huang YS, Yeh CC, et al. Effect on postoperative sore throat of spraying the endotracheal tube cuff with benzydamine hydrochloride, $10 \%$ lidocaine, and 2\% lidocaine. Anesth Analg 2010; 111: 882-6.

4. Al-Qahtani AS, Messahel FM. Quality improvement in anesthetic practice--incidence of sore throat after using small tracheal tube. Middle East J Anaesthesiol 2005; 18: 179-83.

5. Teymourian H, Mohajerani SA, Farahbod A. Magnesium and ketamine gargle and postoperative sore throat. Anesth Pain Med 2015; 5: e22367.

6. Yang C, Jung SM, Bae YK, Park SJ. The effect of ketorolac and dexamethasone on the incidence of sore throat in women after thyroidectomy: a prospective double-blinded randomized trial. Korean J Anesthesiol 2017; 70: 64-71.

7. Lee JH, Kim SB, Lee W, Ki S, Kim MH, Cho K, et al. Effects of topical dexamethasone in postoperative sore throat. Korean J Anesthesiol 2017; 70: 58-63.

8. Moon YE. Postoperative nausea and vomiting. Korean J Anesthesiol 2014; 67: 164-70.

9. Haider HS, Al-Ali BT. The role of dexamethasone in reducing the severity of postoperative sore throat. Iraqi Acad Sci J 2013; 12: 454-9.

10. Zhao X, Cao X, Li Q. Dexamethasone for the prevention of postoperative sore throat: a systematic review and meta-analysis. J Clin Anesth 2015; 27: 45-50.

11. Lee SH, Lee YC, Lee JH, Choi SR, Lee SC, Lee JH, et al. The prophylactic effect of dexamethasone on postoperative sore throat in prone position surgery. Korean J Anesthesiol 2016; 69: 25561.

12. Choung YH, Cho MJ, Kim CH, Lee J, Kang SO. Preliminary results of steroid gargle treatment and clinical characteristics of patients with burning mouth syndrome. Korean J Otolaryn- 
gol-Head Neck Surg 2004; 47: 569-74.

13. Park SY, Kim SH, Lee AR, Cho SH, Chae WS, Jin HC, et al. Prophylactic effect of dexamethasone in reducing postoperative sore throat. Korean J Anesthesiol 2010; 58: 15-9.

14. Brunner E, Domhof S, Langer F. Nonparametric analysis of longitudinal data in factorial experiments. New York, Wiley. 2002.

15. De Oliveira GS Jr, Ahmad S, Fitzgerald PC, Marcus RJ, Altman CS, Panjwani AS, et al. Dose ranging study on the effect of preoperative dexamethasone on postoperative quality of recovery and opioid consumption after ambulatory gynaecological surgery. Br J Anaesth 2011; 107: 362-71.

16. Kim D, Jeon B, Son JS, Lee JR, Ko S, Lim H. The changes of endotracheal tube cuff pressure by the position changes from supine to prone and the flexion and extension of head. Korean J Anesthesiol 2015; 68: 27-31.

17. Mencke T, Echternach M, Kleinschmidt S, Lux P, Barth V, Plinkert PK, et al. Laryngeal morbidity and quality of tracheal intubation: a randomized controlled trial. Anesthesiology 2003; 98: 1049-56.

18. Subedi A, Tripathi M, Pokharel K, Khatiwada S. Effect of intravenous lidocaine, dexamethasone, and their combination on postoperative sore throat: a randomized controlled trial. Anesth Analg 2019; 129: 220-5.

19. Park SY, Kim SH, Lee SJ, Chae WS, Jin HC, Lee JS, et al. Application of triamcinolone acetonide paste to the endotracheal tube reduces postoperative sore throat: a randomized controlled trial. Can J Anaesth 2011; 58: 436-42.

20. Gupta P, Khanna J, Mitramustafi AK, Bhartia VK. Role of pre-operative dexamethasone as prophylaxis for postoperative nausea and vomiting in laparoscopic surgery. J Minim Access Surg 2006; 2: 12-5.

21. Ismail EA, Abo Elfadl GM, Bahloul M. Comparison of intraperitoneal versus intravenous dexamethasone on postoperative nausea and vomiting after gynecological laparoscopy: a randomized clinical trial. Korean J Anesthesiol 2019; 72: 47-52.

22. Yao XL, Cowan MJ, Gladwin MT, Lawrence MM, Angus CW, Shelhamer JH. Dexamethasone alters arachidonate release from human epithelial cells by induction of p11 protein synthesis and inhibition of phospholipase A2 activity. J Biol Chem 1999; 274: 17202-8.

23. Deming MV, Oech SR. Steroid and antihistaminic therapy for post intubation subglottic edema in infants and children. Anesthesiology 1961; 22: 933-6.

24. Seervi SN, Singariya G, Kamal M, Kumari K, Siddeshwara A, Ujwal S. Effect of addition of buprenorphine or dexamethasone to levobupivacaine on postoperative analgesia in ultrasound guided transversus abdominis plane block in patients undergoing unilateral inguinal hernia repair: a prospective randomized double blind controlled trial. Korean J Anesthesiol 2019; 72: $245-52$

25. Jeong SH, Ok SM, Huh JY, Ko MY, Ahn YW. A study for direct application of drug on oral mucosa. J Oral Med Pain 2010; 35: 229-35.

26. Park AR, La HO, Cho BS, Kim SJ, Lee BK, Rhie JY, et al. Comparison of budesonide and dexamethasone for local treatment of oral chronic graft-versus-host disease. Am J Health Syst Pharm 2013; 70: 1383-91.

27. Mayhood J, Cress K. Effectiveness of ketamine gargle in reducing postoperative sore throat in patients undergoing airway instrumentation: a systematic review. JBI Database System Rev Implement Rep 2015; 13: 244-78.

28. Safavi M, Honarmand A, Fariborzifar A, Attari M. Intravenous dexamethasone versus ketamine gargle versus intravenous dexamethasone combined with ketamine gargle for evaluation of post-operative sore throat and hoarseness: a randomized, placebo-controlled, double blind clinical trial. Adv Biomed Res $2014 ; 3: 212$.

29. Cho CK, Kim JE, Yang HJ, Sung TY, Kwon HU, Kang PS. The effect of combining lidocaine with dexamethasone for attenuating postoperative sore throat, cough, and hoarseness. Anesth Pain Med 2016; 11: 42-8.

30. Kim TY. Small but serious risk of perioperative steroid use. Korean J Anesthesiol 2017; 70: 1-2. 